\title{
The current situation of canine dirofilariosis in Hungary
}

\section{Róbert Farkas $^{1} \cdot$ Viktória Mag $^{1} \cdot$ Mónika Gyurkovszky $^{1} \cdot$ Nóra Takács $^{1} \cdot$ Károly Vörös $^{2} \cdot$ Norbert Solymosi $^{3}$}

Received: 9 July 2019 / Accepted: 24 September 2019 /Published online: 21 November 2019

(C) The Author(s) 2019

\begin{abstract}
Between April and September 2017, blood samples were collected from 344 randomly selected dogs older than 1 year in 180 settlements of 19 counties in Hungary. The dogs lived exclusively outdoors, had never travelled and had neither been examined for Dirofilaria infection nor treated against mosquitoes with insecticides or/and filarioid worms with macrocyclic lactones. Dirofilaria infection was examined with a modified Knott's test for microfilariae, DiroCHEK ${ }^{\circledR}$, for the presence of D. immitis antigen, as well as by multiplex and conventional PCR. Altogether, 77 (22.4\%) dogs living in 58 settlements of 17 counties were found to be infected with one or both Dirofilaria species based on the PCR techniques. Twenty-eight (8.1\%) and $38(11.1 \%)$ dogs were infected with $D$. immitis and D. repens, respectively. Coinfections were recorded in 11 samples (3.2\%) collected in 11 locations of 8 counties. The results confirmed that both dirofilarioses are endemic in dogs and the eastern areas of the country are hyperendemic for heartworm disease. Temperature showed a significant association with the prevalence of $D$. immitis (OR 2.41, $95 \%$ CI 1.24-4.86, $p=0.012$ ) but not with that of $D$. repens (OR 1.37, 95\% CI 0.78-2.47, $p=0.286$ ). The prevalence of neither D. immitis (OR 0.99, 95\% CI 0.98-1.00, $p=0.213$ ) nor D. repens (OR 1.01, 95\% CI 0.99-1.01, $p=0.094$ ) showed a significant correlation with precipitation. The number of yearly growing degree days (GDD) based on the lifecycle of Dirofilaria in mosquitoes ranged between 3.73 and 7.57 for the Hungarian districts. The GDD showed a significant positive association with the prevalence of D. immitis (OR 2.38,95\% CI 1.43-4.15, $p=0.001$ ) and a non-significant positive relationship with that of D. repens (OR 1.25, 95\% CI 0.83-1.95, $p=0.291)$.
\end{abstract}

Keywords Dirofilaria immitis $\cdot$ repens $\cdot$ Hungary $\cdot$ Spreading $\cdot$ Spatial pattern $\cdot$ Environmental association

\section{Introduction}

One of the most pathogenic parasites of dogs, Dirofilaria immitis, can cause life-threatening heartworm disease (other name cardiopulmonary dirofilariosis) worldwide (Simón et al. 2012). Dirofilaria repens, the causative agent of subcutaneous dirofilariosis of domestic dogs, occurs in Europe, Asia and Africa only. Both species can infect several other mammalian

Section Editor: Domenico Otranto

Róbert Farkas

farkas.robert@univet.hu

1 Department of Parasitology and Zoology, University of Veterinary Medicine, István u. 2, Budapest H-1078, Hungary

2 Department and Clinic of Internal Medicine, University of Veterinary Medicine, István u. 2, Budapest H-1078, Hungary

3 Centre for Bioinformatics, University of Veterinary Medicine, István u. 2, Budapest H-1078, Hungary species, especially wild canids, such as red foxes, golden jackals, wolves, ferrets and rarely cats (Otranto and Deplazes 2019). In addition, they are zoonotic parasites: $D$. repens causes ocular/subcutaneous while $D$. immitis benign pulmonary dirofilariosis in humans (McCall et al. 2008; Simón et al. 2012; Morchón et al. 2012; Capelli et al. 2018). The infective larvae of these filarioid helminths (Spirurida: Onchocercidae) develop in mosquitoes. About $60-70$ species of the family Culicidae belonging to several genera are regarded as potential intermediate hosts and vectors around the world; however, their vector competence has been proven only in a few cases (McCall et al. 2008).

Until the last decade of the twentieth century, both parasites had occurred mainly in the southern European countries such as Italy, Portugal, Spain, France and Greece, where dirofilariosis was considered to be present historically (Trotz-Williams and Trees 2003; Genchi et al. 2005; Morchón et al. 2012). Recent epidemiological studies have confirmed that both helminths have appeared and become endemic in many countries of Central and Eastern Europe 
where they have caused an increasing number of autochthonous infections among the local dogs (Morchón et al. 2012; Tasić-Otašević et al. 2015; Capelli et al. 2018). The quick geographical spreading of these parasites to European areas where they were not known to be present previously can be explained by several factors. The importance of the increasing length of warm weather periods due to the climate change has to be underlined as one of the major determinants of the development, activity and seasonal survival of mosquitoes as well as of the development of Dirofilaria larvae in the vectors (Medlock et al. 2007; Genchi et al. 2009, 2011). The introduction of the Pet Travel Scheme in 2000 contributed to the spread of dirofilariosis by allowing easier movement of infected, microfilaraemic dogs across Europe from endemic areas (Genchi et al. 2009, 2011).

The first autochthonous $D$. repens infections of dogs were reported at the end of the 1990s in Hungary (Fok et al. 1998; Széll et al. 1999). During the first nationwide epidemiological surveys, the mean prevalence of $D$. repens was $14 \%$ in microfilaraemic dogs (Fok et al. 2007). Heartworm infection was diagnosed in dogs previously living in the USA (Boros et al. 1982; Vörös et al. 2000). Jacsó et al. (2009) reported the first autochthonous $D$. immitis infection of a local dog which lived in the eastern part of the country. Since that time, the number of confirmed heartworm infections has increased (Farkas et al. 2014; Túri and Hetyey 2014; Bacsadi et al. 2016; Trájer et al. 2016; Vörös et al. 2017; Bagi et al. 2017) and worms were found during the necropsy of a ferret (Molnár et al. 2010), some red foxes and golden jackals (Tolnai et al. 2014).

One of the objectives of this study was to get up-to-date information about the geographical distribution of Dirofilariainfected dogs in the country. The association between the prevalence and the climatic conditions was also analysed to describe the relationships quantitatively.

\section{Materials and methods}

\section{Study areas, animals and sampling}

Between April and September 2017, blood samples were collected from 344 randomly selected dogs older than 1 year in 180 settlements of all the 19 counties in Hungary, with the exception of the capital, Budapest (Fig. 1). The number of examined dogs per county was calculated based on the number of animals vaccinated against rabies in 2016. Most of the animals were medium-sized mixed breed dogs, aged between

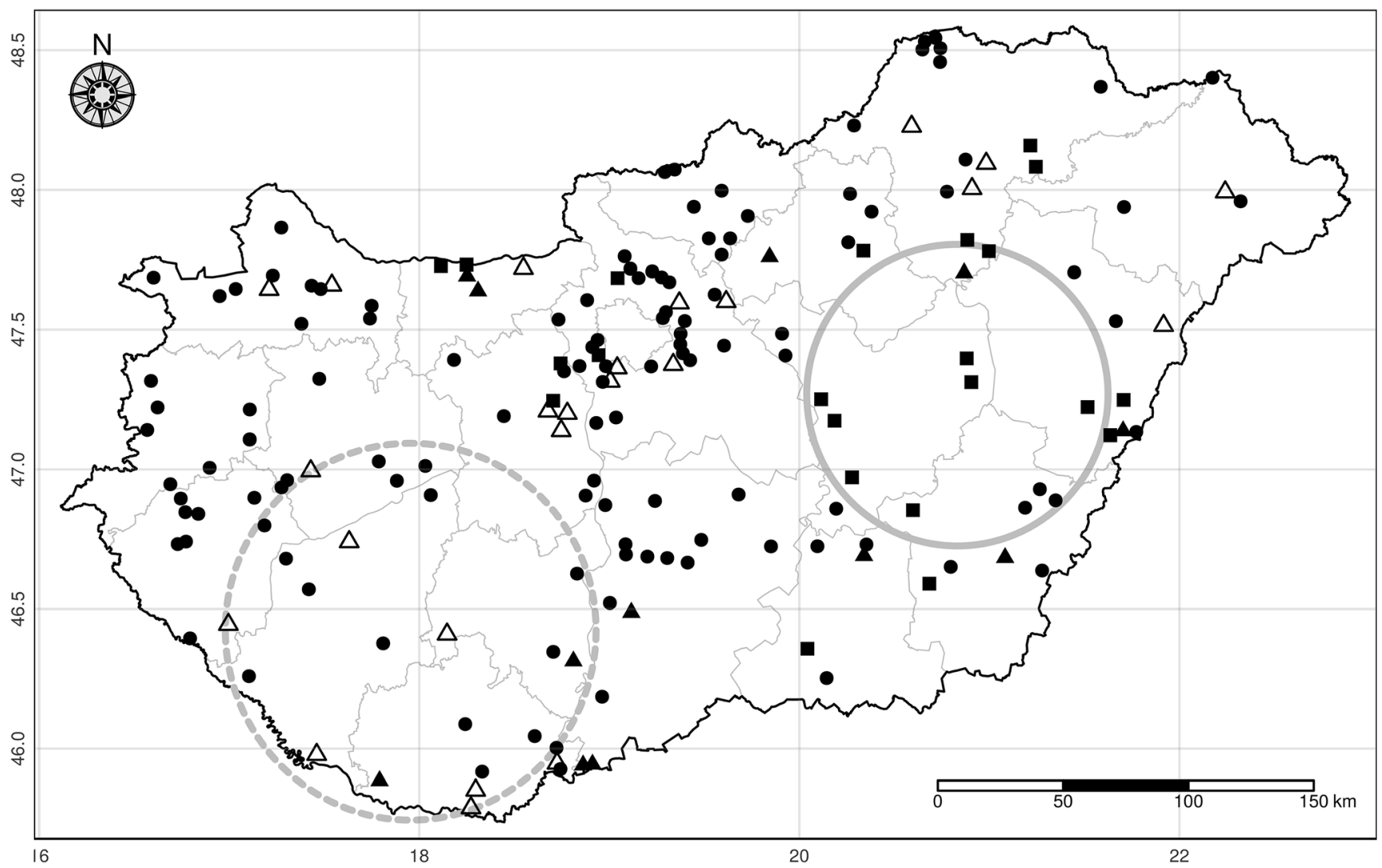

Fig. 1 Sampling locations of the survey. Settlements with no infected dogs are indicated by black dots, while places of infection by $D$. immitis and $D$. repens and by both species are represented by filled boxes, empty triangles and filled triangles, respectively. Detected spatial cluster for $D$. immitis (solid line) and $D$ repens (dashed line) 
1 and 13 years. They lived exclusively outdoors, had never travelled out of their county and had neither been examined for Dirofilaria infection nor treated against mosquitoes with insecticides and filarioid worms with macrocyclic lactones. With the owners' consent, a 2-mL blood sample was withdrawn from the cephalic vein of each dog using two labelled tubes without anticoagulant and with EDTA. After centrifugation, the serum samples were stored at $-20{ }^{\circ} \mathrm{C}$ until further processing.

\section{Examination for microfilariae}

The presence of circulating microfilariae was examined using a modified Knott's test (Genchi et al. 2007).

\section{Serologic assay}

Serum samples were tested for the presence of $D$. immitis antigen produced by adult female heartworms with DiroCHEK ${ }^{\circledR}$ (Synbiotics Corporation, San Diego, USA), in accordance with the manufacturer's instructions.

\section{Molecular identification}

For a specific diagnosis, DNA was isolated from $0.2 \mathrm{~mL}$ of blood from each sample containing microfilariae based on the modified Knott's test using NucleoSpin ${ }^{\circledR}$ Tissue kit (Macherey-Nagel GmbH, Düren, Germany). Multiplex and conventional PCR reactions targeting fragments of $12 \mathrm{~S}$ rDNA of both Dirofilaria spp. and 16S rRNA of D. immitis were used, respectively (Liu et al. 2005; Gioia et al. 2010). In each reaction set, a positive control (DNA extracted from adult nematodes) and a sample with no DNA were included. The PCR products were visualised by gel electrophoresis, and their molecular weight was assessed by comparison to a molecular marker (PCRBIO Ladder IV 100-1500 bp DNA Ladder, PCR Biosystems Ltd., London, UK).

\section{Spatial and climate association analyses}

The prevalence of dirofilariosis was estimated based on the aggregated samples at NUTS 4 level. The spatial clustering was tested by Kulldorff spatial cluster detection method using Poisson likelihood with $50 \%$ as the maximum window size (Kulldorff and Nagarwalla 1995). Environmental associations were analysed by logistic regression. As independent variables, climate data aggregated on level NUTS 4 were applied (Gelman and Hill 2006). The climate variables were calculated using the 2-m temperature and yearly total precipitation obtained with $0.125^{\circ}$ spatial resolution from the ECMWF ERA-Interim daily repository (Dee et al. 2011) for the period 2008-2017. Besides the raw temperature data, the number of Dirofilaria generations based on the growing degree days (GDD) was calculated following the method described by Genchi et al. (2005). For temperature, GDD and precipitation, the yearly average was included in the models. All statistical analyses and visualisation were performed in R ( $\mathrm{R}$ Core Team 2018).

\section{Results}

Altogether, 77 out of the 344 dogs from 58 settlements of 17 counties were found to be infected by one or both Dirofilaria species based on the serological and PCR results (Fig. 1). The overall prevalence of dirofilariosis was $22.4 \%$ (95\% CI 18.30-27.08). Twenty-eight (8.1\%) and $38(11.1 \%)$ dogs were infected with $D$. immitis and $D$. repens, respectively. No occult dirofilariosis occurred. Coinfections were recorded in 11 (3.2\%) samples collected in 11 locations of 8 counties (Fig. 1). The total number of animals with heartworms was 39 (11.3\%): these dogs lived in 34 settlements of 12 counties. The prevalence of $D$. repens was slightly higher (49/344, $14.2 \%$ ); the infected dogs lived in 35 settlements of 16 counties (Fig. 1). By the Kulldorff scan method, a non-identical, significant cluster was identified for D. immitis $(p<$ $0.001)$ and $D$. repens $(p=0.044)$ (Fig. 1). However, nonsignificant $(p=0.07)$ spatial aggregation was found for the pooled data of both species. Temperature showed a significant association with the prevalence of $D$. immitis (OR 2.41, 95\% CI 1.24-4.86, $p=0.012$ ) but not with that of $D$. repens (OR $1.37,95 \%$ CI $0.78-2.47, p=0.286$ ). The prevalence of neither D. immitis (OR $0.99,95 \%$ CI $0.98-1.00, p=0.213$ ) nor D. repens (OR 1.01, 95\% CI 0.99-1.01, $p=0.094$ ) showed a significant correlation with precipitation. The number of yearly GDD-based life cycles of Dirofilaria in vectors ranged between 3.73 and 7.57 for the Hungarian districts (Fig. 2). It showed a significant positive association with the prevalence of D. immitis (OR 2.38, 95\% CI 1.43-4.15, $p=0.001$ ) and a non-significant positive relationship with that of $D$. repens (OR 1.25, 95\% CI 0.83-1.95, $p=0.291$ ).

\section{Discussion}

Although it was suspected that $D$. repens infections had occurred in Hungary between 1879 and 1951 (Kotlán 1951), the first confirmed autochthonous cases of dogs (Fok et al. 1998; Széll et al. 1999) and humans (Szénási et al. 2008) were reported at the end of the twentieth century and later. In the first nationwide epidemiological survey of $826 \mathrm{dogs}, 116(14.0 \%)$ were positive for $D$. repens microfilariae and more than half of them lived along the Danube and Tisza rivers with huge areas of mosquito breeding sites (Fok et al. 2007). A few years later, a higher prevalence $(19.6 \%)$ of D. repens was found when blood samples from 2278 dogs were examined with the 
Fig. 2 The growing degree days (GDD)-based yearly mean lifecycles of Dirofilaria calculated on NUTS 4 level in Hungary from ECMWF ERA Interim daily data for the period 2008-2017

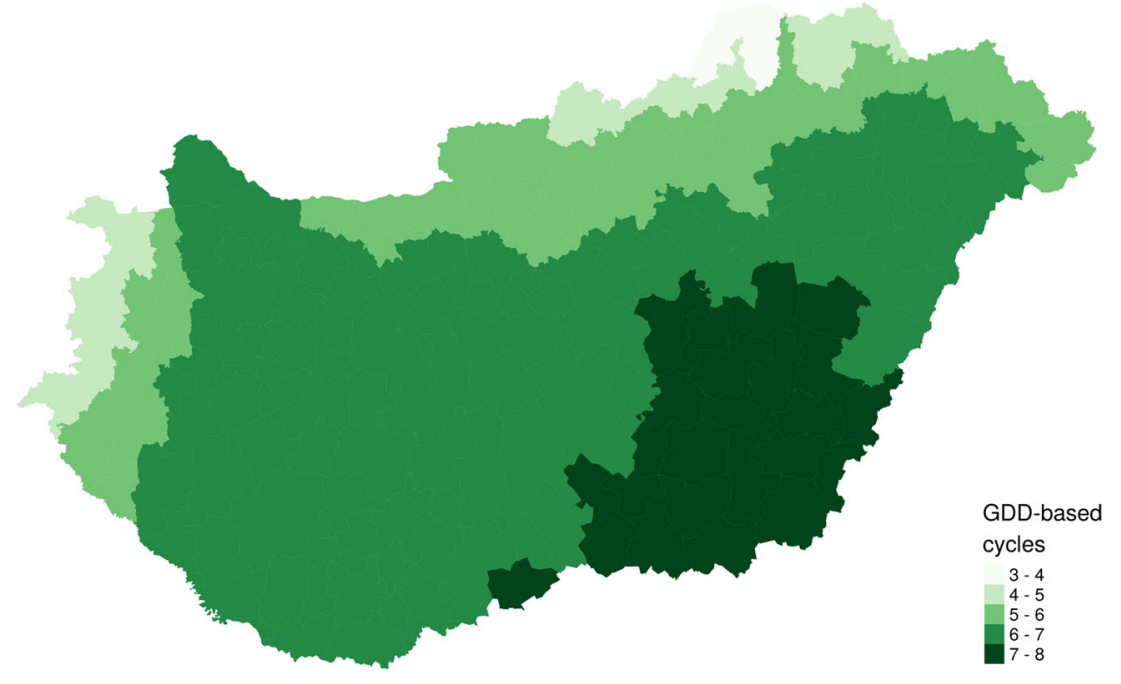

modified Knott method (Jacsó 2014). The result of this study is in line with the previous findings, as the prevalence of $D$. repens was $14.2 \%$. Our results confirm that D. repens is widely distributed in the local dogs, presenting a continuous risk of human infection (Dóczi et al. 2015). Microfilaraemic dogs occurred in 16 counties, but a significant $(p=0.044)$ cluster was found only in a region where $D$. repens was the most frequent filarioid parasite in mosquito samples collected in a 3-year surveillance programme between 2011 and 2013 (Kemenes et al. 2015). Taking into account the previous report about Dirofilaria infections in the country (Kotlán 1951), we suspect that $D$. repens appeared in Hungary and become endemic earlier than the end of the twentieth century as others hypothesised (Genchi et al. 2011; Capelli et al. 2018).

From the beginning of the 2000s, the focus of scientific interest shifted to D. immitis that causes a severe and potentially fatal cardiopulmonary disease in dogs (Simón et al. 2012). According to previous Hungarian reports, heartworm infection had been diagnosed pathologically only in dogs imported from the USA until 2000 (Boros et al. 1982; Vörös et al. 2000). Following the first autochthonous canine heartworm case (Jacsó et al., 2009), a few dozens of infected dogs have been reported (Farkas et al. 2014; Túri and Hetyey 2014; Bacsadi et al. 2016; Trájer et al. 2016; Vörös et al. 2017; Bagi et al. 2017). All of them were considered autochthonous because these animals had been born in Hungary and had never left the country. The prevalence of $D$. immitis obtained in this study is higher (11.3\%) than that found in earlier serological (Farkas et al. 2014) and retrospective surveys based on the necropsy records of 2622 dogs (Bacsadi et al., 2016), indicating that the number of infected dogs has been increasing in the country. Mixed Dirofilaria infections were detected in 11 (3.2\%) dogs in our study. Trájer et al. (2016) also found 5 coinfected dogs in the southern part of Hungary where 18 dogs were infected with $D$. immitis and 12 out of 56 with
D. repens. These findings show that there is no spatial segregation of the two filarioid species in the given areas. The dogs having both dirofilarioses can be infected by mosquitoes of the same or different species as reported from Italy (Genchi et al. 2009). In our study, a few dogs infected with $D$. immitis were found in some counties but there was only one significant ( $p=0.0002)$ cluster in the eastern part of Hungary where the first autochthonous case was diagnosed. It can be stated that this area is hyperendemic for heartworm disease. We assume that more D. immitis-infected local dogs facilitated the spreading of this nematode species there than in the other part of the country. It cannot be excluded definitively that $D$. immitis had also been present in the country before the twenty-first century because no epidemiological surveys had been carried out and no reliable diagnostic methods were available earlier. However, it is more plausible that $D$. immitis has only recently been introduced to Hungary because neither microfilariae nor adult worms of $D$. immitis had been found in local dogs (Fok et al. 2007) and red foxes earlier (Sréter et al. 2003). It is not known yet why D. repens has higher prevalence than $D$. immitis. The dogs infected with this helminth are often asymptomatic, and no specific serological tests are available, while heartworm infections cause severe clinical disease (McCall et al. 2008). There are several inclinic serological test kits for detecting the circulating antigens of female heartworms (Capelli et al. 2018). Although Genchi et al. (2005) assumed the same requirements for the development of both species, further research is needed to study the effect of temperature on $D$. repens.

In Hungary, the occurrence and spread of both filarioid species are not surprising because the local climate and the abundance of mosquito vectors offer suitable conditions for the development and transmission of these parasites. The question to be answered is how these nematodes arrived and spread in the country. A possibility is that they were 
introduced from a neighbouring country where they had been reported. In a long-term monitoring carried out in Slovakia between 2005 and 2015, D. immitis was detected in 10 dogs of which 9 had mixed infection, and some autochthonous cases were revealed in the Komárno district, close to the border of Hungary (Čabanová et al. 2015; Miterpáková et al. 2016). In Serbia, a high prevalence of both species had been found in dogs (Tasić et al. 2008, 2012; Krstić et al., 2017). There are some reports about the prevalence and distribution of Dirofilaria spp. from Romania, too. Depending on the methods and sampling areas, significant variations of single and mixed dirofilarioses of dogs have been reported (Mircean et al. 2012; Ionică et al. 2015). It might be possible that infected red foxes and/or golden jackals arrived from Romania (Ionică et al. 2017) or Serbia (Penezić et al. 2014) where Dirofilaria infection of these wild canids was detected, which underlines their role as reservoir hosts in the dissemination of these nematodes. Hungarian authors (Kemenesi et al. 2015) reported that golden jackals may also facilitate the persistence of $D$. repens and could naturally widen the distribution area of that parasite. Nevertheless, we do not think that the role of wild canids should be considered regarding the geographical distribution of dirofilariosis in Hungary because only a few red foxes and two golden jackals shot in 8 counties were found to be infected, having a low number of heartworms without microfilaraemia (Tolnai et al. 2014). Marconcini et al. (1996) also found low numbers of adult heartworms in foxes without microfilaraemia. It is more plausible that the infection of the local wild canids may have originated from infected dogs inhabiting the same areas. We also hypothesise that local mosquitoes could be infected with microfilariae of Dirofilaria spp. originally from dogs infected abroad like those which arrived in Hungary with their owners for hunting from endemic countries. Stray dogs and dogs adopted from shelters pose a high risk in the epidemiology of both dirofilarioses because they are unlikely to receive proper examination and prevention. The likelihood of other carnivores such as cats or ferrets being involved in the transmission of Dirofilaria spp. should not be considered because microfilaraemia is absent or short-lasting in these hosts (Campbell and Blair 1978; McCall et al. 2008; Bajer et al. 2016). The chance that Dirofilaria spp. were introduced to Hungary with infected mosquitoes is very small, because the movement and ranges of these insects are limited (Genchi et al. 2005; Tsuda et al. 2008; Zittra et al. 2015). However, the importance of mosquitoes carried by the wind and humans in the geographical distribution of vector-borne pathogens cannot be excluded. To date, Dirofilaria infection in the local mosquitoes is scarcely known. Among 50 mosquito species known to be present in the country (Kenyeres and Tóth 2012), the specimens of the Culex pipiens complex seem to be important vectors of Dirofilaria spp. (Zittra et al. 2015) like in other European countries (Cancrini et al. 2006, Morchón et al. 2007; Čabanová et al. 2018). Some specimens of other mosquito species such as $C x$. modestus and Ocreatus caspius infected with Dirofilaria larvae were caught in Southern Hungary. The potential involvement of Oc. sticticus mosquitoes in the natural transmission cycle of the parasites was also reported from the country (Kemenesi et al. 2015; Zittra et al. 2015). Taking into account the two main preconditions of the transmission of Dirofilaria spp. (Simón et al. 2012), we hypothesize that the presence of a minimum number of dogs infected with adult worms producing microfilariae facilitated establishment of both parasite species in the country.

More than a decade ago, Genchi et al. (2005) used temperature records obtained from all over Europe from 1977 to 1991 to predict the likely number of Dirofilaria generations in Europe. They reported that the yearly average predicted number of heartworm generations for Hungary was between 1 and 5. Following their method, we calculated the number of yearly growing degree days (GDD) using temperature data for the period 2008 through 2017. We obtained a higher estimate for the number of Dirofilaria generations per year. This can be explained by the increasing temperature due to global warming. Another possible reason for the differences might be the distinct sources of the applied meteorological datasets. The risk period for Dirofilaria transmission is seasonal in Hungary, with peaks in the summer, when the temperature is especially sufficient to facilitate the extrinsic incubation of Dirofilaria in vectors. We are aware of the fact that environmental temperature along with adequate moisture is one of the key factors in the epidemiology of dirofilariosis as others have stated (Medlock et al. 2007; Genchi et al. 2009). However, the movement of unprotected dogs against mosquitoes and dirofilariosis and other factors such as the population density of vectors and hosts, the potential mosquito-breeding habitats and the veterinarians' awareness of the infection also play a critical role in the geographical distribution of both filarioid species.

\section{Conclusions}

Both dirofilarioses are endemic in Hungary, and heartworm disease is more prevalent in the eastern areas of the country. This study further confirms the significant circulation of these filarioid parasites in the local domestic dogs. We assume that the administration of broad-spectrum chemoprophylactic products with endoparasiticidal and/or ectoparasiticidal activity for 8-12 months each year would assist in preventing these pathogenic and zoonotic parasitic infections. Further systematic monitoring studies are required to better understand the environmental risk factors and to identify the competent mosquito vectors in the epidemiology of local dirofilariosis. Particular attention should be paid to stray and shelter dogs. 
Acknowledgements The authors are grateful to all owners and veterinarians who kindly collaborated in this research.

Funding Information Open access funding provided by University of Veterinary Medicine (ÁTE).

Compliance with ethical standards The blood samples were taken with the owner's approval. All animals were sampled by a veterinarian to ensure that no dogs suffered any harm according to current regulations.

Conflict of interest The authors declare that they have no conflict of interest.

Open Access This article is distributed under the terms of the Creative Commons Attribution 4.0 International License (http:// creativecommons.org/licenses/by/4.0/), which permits unrestricted use, distribution, and reproduction in any medium, provided you give appropriate credit to the original author(s) and the source, provide a link to the Creative Commons license, and indicate if changes were made.

\section{References}

Bacsadi Á, Papp A, Szeredi L, Tóth G, Nemes C, Imre V, Tolnai Z, Sréter T (2016) Retrospective study on the distribution of Dirofilaria immitis in dogs in Hungary. Vet Parasitol 220:83-86

Bagi F, Vörös K, Túri A (2017) Preliminary experiences of the diagnosis and complex treatment of canine heart-worm disease: 38 cases. Magy Allatorvosok Lapja 139:203-213 (in Hungarian)

Bajer A, Rodo A, Mierzejewska EJ, Tolkacz K, Welc-Faleciak R (2016) The prevalence of Dirofilaria repens in cats, healthy dogs and dogs with concurrent babesiosis in an expen-sion zone in central Europe. BMC Vet Res 12:183

Boros G, Janisch M, Sebestyén G (1982) Dirofilaria immitis in dogs. Magy Allatorvosok Lapja 37:313-316 (in Hungarian)

Čabanová V, Miterpáková M, Valentová D, Blažejová H, Rudolf I, Stloukal E, Hurníková Z, Dzidová M (2018) Urbanization impact on mosquito community and the transmission potential of filarioid infection in Central Europe. Parasit Vectors 11:261

Čabanová V, Pantchev N, Hurníková Z, Miterpáková M (2015) Recent study on canine vector-borne zoonoses in southern Slovakia - serologic survey. Acta Parasitol 60:749-758

Campbell WC, Blair LS (1978) Dirofilaria immitis: experimental infections in the ferret (Mustela putorius furo). J Parasitol 64:119-122

Cancrini G, Magi M, Gabrielli S, Arispici M, Tolari F, Dell'Omodarme M, Prati MC (2006) Natural vectors of dirofilariasis in rural and urban areas of the Tuscan region, central Italy. J Med Entomol 43: $574-579$

Capelli G, Genchi C, Baneth G, Bourdeau P, Brianti E et al (2018) Recent advances on Dirofilaria repens in dogs and humans in Europe. Parasit Vectors 11:663

Dee DP, Uppala SM, Simmons AJ, Berrisford P, Poli P et al (2011) The ERA-Interim reanalysis: configuration and performance of the data assimilation system. Q J R Meteorol Soc 137:553-597

Dóczi I, Bereczki L, Gyetvai T, Fejes I, Skribek Á, Szabó Á, Berkes S, Tiszlavicz L, Kucsera I (2015) Description of five dirofilariasis cases in South Hungary and review epidemiology of this disease for the country. Wien Klin Wochenschr 127:696-702

Farkas R, Gyurkovszky M, Lukács Z, Aladics B, Solymosi N (2014) Seroprevalence of some vector-borne infections of dogs in Hungary. Vector Borne Zoonotic Dis 14:256-260
Fok É, Kiss G, Majoros G, Jacsó O, Farkas R, Gyurkovszky M (2007) Preliminary results of an epidemiological survey on dirofilariosis of dogs and cats in Hungary. In: Genchi C, Rinaldi L, Cringoli G (eds) Dirofilaria immitis and D. repens in dog and cat and human infections. Roland Editore, Napoli, pp 194-196

Fok É, Szabó Z, Farkas R (1998) The first autochthonous case of a dog infected with Dirofilaria repens in Hungary. Kisállatorvoslás 4:218 219 (in Hungarian)

Gelman A, Hill J (2006) Data analysis using regression and multilevel/ hierarchical models. Cambridge University Press

Genchi C, Mortarino M, Rinaldi L, Cringoli G, Traldi G, Genchi M (2011) Changing climate and changing vector-borne disease distribution: the example of Dirofilaria in Europe. Vet Parasitol 176:295299

Genchi C, Rinaldi L, Cascone C, Mortarino M, Cingoli G (2005) Is heartworm really spreading in Europe? Vet Parasitol 133:137-148

Genchi C, Rinaldi L, Mortarino M, Genchi M, Cringoli G (2009) Climate and Dirofilaria infection in Europe. Vet Parasitol 163:286-292

Genchi C, Venco L, Genchi M (2007) Guideline for the laboratory diagnosis of canine and feline Dirofilaria infections. In: Genchi C, Rinaldi L, Cringoli G (eds) Dirofilaria immitis and D. repens in dog and cat and human infections. Rolando Editore, Naples, pp $137-144$

Gioia G, Leccová L, Genchi M, Ferri E, Genchi C, Mortarino M (2010) Highly sensitive multiplex PCR for simultaneous detection and discrimination of Dirofilaria immitis and Dirofilaria repens in canine peripheral blood. Vet Parasitol 172:160-163

Ionică AM, Matei IA, Mircean V, Dumitrache MO, D'Amico G, Győrke A, Pantchev N, Annoscia G, Albrechtová K, Otranto D, Modrý D, Mihalca AD (2015) Current surveys on the prevalence and distribution of Dirofilaria spp. and Acanthocheilonema reconditum infections in dogs in Romania. Parasitol Res 114:975-982

Ionică AM, Matei IA, D'Amico G, Ababii J, Daskalaki AA, Sándor AD, Enache V, Gherman CM, Mihalca AD (2017) Filarioid infections in wild carnivores: a multispecies survey in Romania. Parasit Vectors $10: 332$

Jacsó O, Mándoki M, Majoros G, Pétsch M, Mortarino M, Genchi C, Fok E (2009) First autochthonous Dirofilaria immitis (Leidy, 1856) infection in a dog in Hungary. Helmintologia 46:159-161

Jacsó O (2014) Distribution of Dirofilaria spp. in Hungary and their veterinary importance, the experience of the treatment. Dissertation. University of Veterinary Medicine, Budapest (in Hungarian)

Kemenesi G, Kurucz K, Kepner A, Dallos B, Oldal M, Herczeg R, Vajdovich P, Bányai K, Jakab F (2015) Circulation of Dirofilaria repens, Setaria tundra and Onchocercidae species in Hungary during the period 2011-2013. Vet Parasitol 214:108-113

Kenyeres Z, Tóth S (2012) Landscape-structure determined mosquito diversity in Hungary (Central Europe). J Mosq Res 5:32-38

Kotlán A (1951) On a new case of human filarioidosis in Hungary. Acta Vet Acad Sci Hung 1:69-79

Krstić M, Gabrielli S, Ignjatović M, Savić S, Cancrini G, Ranđelović G, Momčilović S, Stojnev S, Otašević S (2017) An appraisal of canine and human cases reveals an endemic status of dirofilariosis in parts of Serbia. Mol Cell Probes 31:37-41

Kulldorff M, Nagarwalla N (1995) Spatial disease clusters: detection and Inference. Stat Med 14:799-810

Liu J, Song KH, Lee SE, Lee JY, Lee JI, Hayasaki M, You MJ, Kim DH (2005) Serological and molecular survey of Dirofilaria immitis infection in stray cats in Gyunggy province, South Korea. Vet Parasitol 130:125-129

Marconcini A, Magi M, Macchioni G, Sassetti M (1996) Filariosis in foxes in Italy. Vet Res Commun 20:316-319

McCall JW, Genchi C, Kramer LH, Guerrero J, Venco L (2008) Chapter 4, heartworm disease in animals and humans. Adv Parasitol 66:193-285 
Medlock JM, Barras I, Kerrod E, Taylor MA, Leach S (2007) Analysis of climatic predictions for extrinsic incubation of Dirofilaria in the United Kingdom. Vector Borne Zoonotic Dis 7:4-14

Mircean V, Dumitrache MO, Györke A, Pantchev N, Jodies R, Mihalca AD, Cozma V (2012) Seroprevalence and geographic distribution of Dirofilaria immitis and and tick-borne infections (Anaplasma phagocytophilum, Borrelia burgdorferi sensu lato and Ehrlichia canis) in dogs from Romania. Vector Borne Zoonotic Dis 12:595604

Miterpáková M, Iglódyová A, Čabanová V, Stloukal E, Miklisová D (2016) Canine dirofilariosis endemic in Central Europe 10 years of epidemiological study in Slovakia. Parasitol Res 116:2389-2395

Molnár V, Pazár P, Rigó D, Máthé D, Fok E, Glávits R, Vajdovich P, Jacsó O, Balogh L, Sós E (2010) Autochthonous Dirofilaria immitis infection in ferret with aberrant larval migration in Europe. J Small Anim Pract 51:393-396

Morchón R, Bargues MD, Latorre JM, Melero-Alcíbar R, Pou-Barreto C, Mas-Coma S, Simón F (2007) Haplotype H1 of Culex pipiens implicated as a natural vector of Dirofilaria immitis in an endemic area of Western Spain. Vector Borne Zoonotic Dis 7:653-658

Morchón R, Carretón E, González-Miguel J, Mellado-Hernández I (2012) Heartworm disease (Dirofilaria immitis) and their vectors in Europe - new distribution trends. Front Physiol 196:1-11

Otranto D, Deplazes P (2019) Zoonotic nematodes of wild carnivores. IJP: Parasites and Wildlife 9:370-383

Penezić A, Selaković S, Pavlović I, Ćirović D (2014) First findings and prevalence of adult heartworms (Dirofilaria immitis) in wild carnivores from Serbia. Parasitol Res 113:3281-3285

R Core Team (2018) R: A language and environment for statistical computing. In: R Foundation for Statistical Computing. Vienna, Austria URL https://www.R-project.org/

Simón F, Siles-Lucas M, Morchón R, González-Miguel J, Mellado I, Carretón E, Montoya-Alonso JA (2012) Human and animal dirofilariasis: the emergence of a zoonotic mosaic. Clin Microbiol Rev 25:507-544

Sréter T, Széll Z, Marucci G, Pozio E, Varga I (2003) Extraintestinal nematode infections of red foxes (Vulpes vulpes) in Hungary. Vet Parasitol 148:365-370

Széll Z, Sréter T, Csikós K, Katai Z, Dobos-Kovács M, Vetési F, Varga I (1999) Autochthonous infection with Dirofilaria repens in dogs in Hungary. Magy Allatorvosok Lapja 121:100-104 (in Hungarian)

Szénási Z, Kovács AH, Pampiglione S, Fioravanti ML, Kucsera I, Balázs T, Tiszlavicz L (2008) Human dirofilariosis in Hungary: an emerging zoonosis in central Europe. Wien Klin Wochenschr 120:96-102
Tasić A, Tasić-Otašević S, Gabrielli S, Miladinović-Tasić N, Ignjatović A, Djordjević J, Dimitrijević S, Cancrini G (2012) Canine Dirofilaria infections in two uninvestigated areas of Serbia: epidemiological and genetic aspects. Vector Borne Zoonotic Dis 12: $1031-1035$

Tasić A, Rossi L, Tasić S, Miladinović-Tasić N, Ilić T, Dimitrijević S (2008) Survey of canine dirofilariosis in Vojvodina, Serbia. Parasitol Res 103:1297-1302

Tasić-Otašević SA, Trenkić Božinović MS, Gabrielli SV, Genchi C (2015) Canine and human Dirofilaria infections in the Balkan Peninsula. Vet Parasitol 209:151-156

Tolnai Z, Széll Z, Sproch Á, Szeredi L, Sréter T (2014) Dirofilaria immitis an emerging parasite in dogs, red foxes and golden jackals in Hungary. Vet Parasitol 203:339-342

Trájer A, Rengei A, Farkas-Iványi K, Bede-Fazeka Á (2016) Impacts of urbanisation level and distance from potential natural mosquito breeding habitats on the abundance of canine dirofilariosis. Acta Vet Hung 64:340-359

Trotz-Williams LA, Trees AJ (2003) Systematic review of the distribution of the major vector-borne parasitic infections in dogs and cats in Europe. Vet Rec 152:97-105

Tsuda Y, Komagata O, Kasai S, Hayashi T, Nihei N, Saito K, Mizutani M, Kunida M, Yoshida M, Kobayashi M (2008) A mark-releaserecapture study on dispersal and flight distance of Culex pipiens pallens in an urban area of Japan. J Am Mosq Control Assoc 24: 339-343

Túri Á, Hetyey Cs (2014) First report of Dirofilaria immitis in the arteria pulmonalis in Hungary, imaged by ultrasonography. Magy Allatorvosok Lapja 136:231-233 (in Hungarian)

Vörös K, Becker Zs, Arany-Tóth A, Gyurkovszky M, Farkas R (2017) Occult D. immitis heartworm disease in a dog. Magy Allatorvosok Lapja 139:675-685 (in Hungarian)

Vörös K, Kiss G, Baska F, Bagdi N, Széll Z (2000) Heartworm disease in dogs. Review article and case report. Magy Allatorv Lapja 122:106108 (in Hungarian)

Zittra C, Kocziha Z, Pinnyei S, Harl J, Kieser K, Laciny A, Eigner B, Silbermayr K, Duscher GG, Fok É, Fuehrer HP (2015) Screening blood-fed mosquitoes for the diagnosis of filarioid helminths and avian malaria. Parasit Vectors 8:16

Publisher's note Springer Nature remains neutral with regard to jurisdictional claims in published maps and institutional affiliations. 